\title{
As Tecnologias de Informação e Comunicação na Formação de Professores no Ensino de Ciências
}

\author{
Lucimeire A parecida Garcia* \\ Vilma da Silva Lins
}

R esumo: Considerando a formação continuada dos profissionais em educação para o uso das tecnologias de informação e comunicação no processo de aperfeiçoamento de práticas pedagógicas, 0 referido trabalho objetivou, a partir de capacitação oferecida pelo NTE - N úcleo de Tecnologia Educacional de D ourados-M S -, reflexões e práticas si gnificativas durante a realização do estágio supervisionado de acadêmicos do curso de Ciências Biológicas da UFGD - U niversidade Federal da Grande D ourados. A metodologia de desenvolvimento de projetos educativos foi aplicada em escolas da rede pública de ensino, havendo como técnica, a construção de mapas conceituais com base na teoria ausebeliana. O s projetos foram desenvolvidos com a interação dos recursos tecnológicos às atividades em sala de aula, apresentando experiências positivas para o ensino aprendizagem.

Palavras-chave: Estágio supervisionado, TIC, M apa conceitual, Projetos pedagógicos.

Professora Especialista do N úcleo de Tecnologia Educacional de Dourados/Secretaria Estadual de E ducação de M S/PR O IN FO - Programa N acional de Informática na Educação. E-mail: lucimeireg@ hotmail.com

* Professora M Sc Substituta da U niversidade Federal da Grande D ourados, no período de 2004 a 2006. Professora do N úcleo de Tecnologia Educacional de D ourados/M S. E-mail: vilins_biol@yahoo.com.br 


\begin{abstract}
A bstract: Considering the continued formation of the professionals in education for the use of the information technologies and communication in the practical process of perfectioning of pedagogical, the related work objectified from qualification offered for the NTE - N úcleo deTecnologiaE ducacional deD ourados-, significant practical reflections and during the accomplishment of the supervised period of training of academics of the course of Biological Sciences of the U FGD - U niversidade Federal da Grande D ourados. Themethodology of development of educative projects was applied in schools of the public net of education, having as technique, the construction of conceptual maps on the basis of the ausebeliana theory. The projects had been developed with the interaction of thetechnological resources to the activities in classroom, presenting positive experiences for education learning.
\end{abstract}

Keywords: Supervised period of training, TIC , Conceptual map, Pedagogical projects.

\title{
Introdução
}

A introdução de novas tecnologias na escola deve ser coerente com um novo modo de agir do professor, favorecendo a criação de um ambiente criativo em que a sua ação mediadora possa ser eficientemente exercida. Ao discutir as dificuldades da formação do professor no contexto do uso das tecnologias, aponta para a necessidade de redefinição do papel do professor, para que esse também desenvolva uma visão social da sua função como professor (RIPPER, 1996).

A inserção das Tecnologias da Informação e Comunicação (TICS) nas escolas públicas já se tornou um processo irreversível. O PRO INFO - Programa N acional de Informática na Educação - lançado em 1997 pela Secretária de E ducação a Distância - SEED/MEC - teve como objetivos: melhorar a qualidade do processo de ensino-aprendizagem; possibilitar a criação de uma 
nova ecologia cognitiva nos ambientes escolares mediante incorporação adequada das novas tecnologias da informação pelas escolas; propiciar uma educação voltada para o desenvolvimento científico e tecnológico eeducar para uma cidadania global numa sociedade tecnologicamente desenvolvida (BRASIL, 1997). Atualmente, o Programa N acional deFormação C ontinuada em Tecnologia E ducacional (PR O IN FO INTEGRADO), instituído pelo D ecreto $\mathrm{n}$ 0 6.300, de 12 de dezembro de 2007, postula a integração e articulação de três componentes: a instalação de ambientes tecnológicos nas escolas, a formação continuada dos professores e outros agentes educacionais para o uso pedagógico das Tecnologias de I nformação e Comunicação e a disponibilização de conteúdos e recursos educacionais multimídia e digitais, soluções e sistemas de informação, disponibilizados pela SEED/M EC.

D iante das novas Tecnologias de I nformação e Comunicação, verifica-se a obtenção e utilização de informações, por meio do computador, e a sensibilização dos aprendizes para a presença de novos recursos tecnológicos no cotidiano. Segundo Almeida (1997), Valente (1993) e Brasil (1998), tais TIC s preparam estudantes para o mundo tecnológico ecientífico, buscando a integração dos mesmos ao trabalho e ao desenvolvimento individual einterpessoal, aproximando assim a escola do mundo real e contextualizado.

As inovações e mudanças educacionais, segundo M oran (2000), dependem de educadores maduros, intelectual e emocionalmente, pessoas curiosas, entusiasmadas, abertas, que saibam motivar e dialogar, educadores que facilitem todo o processo, de organizar a aprendizagem. 0 mesmo autor também destaca que as tecnologias de informática podem trazer, hoje, dados, imagens, resumos de forma rápida e atraente e que, diante disso, o papel principal do professor é ajudar o aluno a interpretar esses dados, relacioná-los e contextualizá-los a situações reais.

Os novos esquemas cognitivos, com o desenvolvimento da cibercultura, entre outros fatores, vêm possibilitando, na área da educação, novas compreensões sobre o processo de ensinar e aprender, calcadas em recursos que conectam e criam relações 
entre sujeitos, pelas diversas redes de informação que vão sendo constituídas - do mundo científico, artístico e cultural. Estes recursos comunicacionais, ao produzirem novas relações do sujeito social com o conhecimento, modificam o papel do emissor e reconfiguram o espaço do receptor, servindo de suporte para mudanças (M ACIEL, 2002). Ao viabilizarem outra relação dialógica, baseada na multidirecionalidade, estabelecem também a "possibilidade de co-criação do conhecimento e de propostas de solução criativa às demandas institucionais e educacionais" (M ACIEL; PAIVA, 2000, apud MACIEL, 2002).

0 professor, tal como o aluno, acaba por ter de estar sempre a aprender. D essemodo, aproxima-sedos seusalunos. D eixade ser a autoridade incontestada do saber para passar a ser, muitas vezes, aquele que menos sabe. A ssim, professor ealuno passam a ser parceiros de um mesmo processo de construção do conhecimento. (PON TE, 2000)

No entanto, alguns professores preferem não enfrentar essas situações e, ao perceberem a dimensão do que ocorre na atividade mediada pelas TICs, não se arriscam e começam a evitar o uso; ou ainda utilizam, mas de uma forma que possam ter um maior controle sobre os alunos (PEN TEAD 0, 1999). Existem também realidades em que o professor, ao aderir ao processo inovador, soma-se e colabora nas propostas e processos de mudanças. Para M oran (2003) "os papéis dos professores se multiplicam, diferenciam e complementam, exigindo uma grande capacidade de adaptação, de criatividade diante de novas situações, propostas, atividades".

\section{Pressupostos teóricos}

Ao refletir a formação do profissional em Educação, percebe-se a preocupação das instituições de ensino em preparar professores competentes e aptos para o desempenho de suas habilidades junto ao ambiente escolar, em que, conforme Freire (1988) e Brasil (1998), o educador tem a função de ser o mediador entre o saber cotidiano e os conhecimentos científicos, orientando os 
alunos a compreender e tomar decisões mediante desafios propostos pela sociedade nos aspectos sociais, políticos, econômicos e culturais.

As atuais exigências do mercado de trabalho mostram, através dos avanços tecnológicos, que o profissional em educação deve estar sempre aberto para mudanças de postura frente às novas metodologias de ensino. Assim, o educador necessita entender a aliança que envolve os anseios sociais presentes nos dias de hoje, em que, entre elas, estão as novas tecnologias de informação e comunicação e os trabalhos desenvolvidos através de projetos educativos.

A escola de hoje deve se preocupar em formar um cidadão autônomo, crítico e criativo, que utilize o conhecimento para inovar, fazendo e se fazendo oportunidade histórica, bem como estabelecendo relações entre o novo conhecimento e o saber acumulado. Para isso, o que se aprende na escola deve aparecer na vida. (DEM O, 2003, p. 17)

$\mathrm{O}$ u "aquilo que se aprende deve ter relação com a vida dos alunos e dos professores, ou seja, deve ser interessante para eles" (HERNANDEZ, 1998, p. 27).

0 papel do professor, que, num passado recente, era de informações, passa a ser o de orientador e questionador, estimulando o aluno a buscar respostas. N este novo desafio docente, o computador é um instrumento importante, pois pode ajudar na organização do pensamento e contribuir para a busca de respostas que auxiliem o sujeito na elaboração do conhecimento (PAIS, 2002).

Encontra-se, na pesquisa de Frant (2001), sobre análise de produção de alunos e professores, uma nova visão sobre o uso de ambientes informatizados. M uitos pesquisadores investigam a utilização do computador como ferramenta que facilita a aprendizagem, fazendo uma ponte entre o aprendiz eo conhecimento, defendendo o uso da tecnologia como forma de expressão. Enfatiza-se que a ferramenta em si não dá conta da aprendizagem, é apenas um meio que pode facilitar os papéis que a tecnologia pode assumir. 
Fiorentini e Castro (2003) afirmam que muitas dificuldades podem ser apresentadas quando o estagiário realiza algumas atividades em um ambiente informatizado. As incertezas poderão ser ainda maiores, pois a sua formação, muitas vezes, não contempla a utilização desses recursos.

Cláudio e Cunha (2001) analisaram a situação das escolas. O s pesquisadores constataram que o professor não se sente preparado para utilizar o computador e não compreende a sua importância no contexto em que atua.

No entanto, é fundamental que o professor tenha, durante sua formação e também em ambiente de trabalho, apoio e incentivo para tal utilização. É um desafio e uma necessidade das universidades, buscarem iniciativas de preparação aos acadêmicos ao mercado de trabalho e às exigências atuais da educação. A credita-se que essa promoção acelera o processo de inovação do ensino, pois formar profissionais não aptos para o exercício de sua função faz com que o sistema venha a disponibilizar práticas de formação básica sempre que houver professores recém-formados.

$N$ este sentido, pode-se concordar com a afirmação de que

(...) os cursos de formação de professores não podem mais propor espaços isolados para a experiência prática, quefaz com que, por exemplo, o estágio se configure como algo com finalidade em si mesmo e se realize de modo desarticulado com o restante do curso (RELA et al, 2007).

N esse sentido, cabe aos professores planejar a organização curricular de forma a possibilitar a articulação entre o saber e o saber fazer. Propor oficinas, seminários, grupos de trabalho supervisionado, com vistas a promover e ao mesmo tempo exigir dos futuros professores atuações diferenciadas, diferentes modos de organização do trabal ho, possibilitará a vivência e o desvelamento de diferentes competências.

Por isso, as instituições de formação inicial têm forte responsabilidade na formação de professores para que estejam abertos à mudança, tenham gosto pela aprendizagem contínua e receptividade à inovação pedagógica. U sar com critério e criticamente as tecnologias, incluindo a capacidade de aprender a lidar com 
novos softwares e equipamentos é parte fundamental na preparação do futuro professor (PONTE; SERRAZIN A, 1998).

Segundo O liveira, Ponte e Varandas (2003), os cursos de formação inicial devem levar em conta a importância do desenvolvimento nos respectivos formandos de diversas competências, no que se refere ao uso das TICs no processo de ensino e aprendizagem. Isso inclui, nomeadamente: usar softwares utilitários (processador de textos, planilhas de cálculo, apresentações na forma de slides etc.); usar e avaliar softwares educativos; integrar as TICs em situações de ensino e aprendizagem; enquadrar as TICS num novo paradigma do conhecimento e aprendizagem, e conhecer as implicações sociais e éticas das TICs.

Assim, além da necessidade de dominar as novas tecnologias educacionais, os professo res percebem que é preciso ocorrer mudanças metodológicas em sala de aula, pois não basta saber usar o computador, mas também saber como utilizá-lo no ensino-aprendizagem. Sugestões para suprir essas necessidades são enfatizadas. As formas de trabalhos por projetos educativos é uma das alternativas de trabalho coletivo, integrado e participativo (HER NÁNDEZ, 1998), o qual procura envolver educandos, educadores, pesquisadores e demais membros da comunidade escolar, em um constante aprender-ensinar, transformando o saber do cotidiano em conhecimento elaborado.

Para desenvolver uma prática pedagógica voltada para a integração das mídias, uma das possibilidades tem sido o trabaIho por projetos. $\mathrm{N}$ a perspectiva da pedagogia de projetos, o aluno aprendefazendo, aplicando aquilo que sabe e buscando novas compreensões com significado para aquilo que está produzindo (FREIRE; PRAD 0, 1999; AL MEIDA, 2002; PRAD 0, 2005a). A s atividades organizadas na forma de projetos de ensino/aprendizagem podem apresentar várias técnicas visando à aprendizagem significativa dos aprendizes como o desenvolvimento de atividades organizadas através de mapas conceituais.

A proposta de trabalho através dos M apas Conceituais, baseada na ideia fundamental da Psicologia Cognitiva de Ausubel, 
a qual estabelece que a aprendizagem ocorra por assimilação de novos conceitos e proposições na estrutura cognitiva do aluno, em que novas ideias e informações são aprendidas, na medida em que existem pontos de ancoragem, implica modificações na estrutura cognitiva e não apenas em acréscimos.

A ssim, a teoria que está por trás do mapeamento conceitual é a teoria cognitiva de aprendizagem (AU SU BEL et al., 1978, 1980; MOREIRA; MASINI, 1982; MOREIRA, 1983). Tratase, no entanto, de uma técnica desenvolvida em meados da década de setenta, por J oseph N ovak e seus colaboradores, na U niversidade de Cornell, nos Estados U nidos, pois Ausubel nunca falou de mapas conceituais em sua teoria. 0 mapeamento conceitual é uma técnica muito flexível e, em razão disso, pode ser usado em diversas situações, para diferentes finalidades: instrumento de análise do currículo, técnica didática, recurso deaprendizagem e meio de avaliação (M OREIRA; BU CH WEITZ, 1993).

Considerando as citações anteriores, pode-se refletir o quanto é essencial promover momentos de formação acadêmica que estimule o preparo do futuro profissional para utilizar tanto as novas tecnologias educacionais quanto as novas metodologias inseridas no processo de ensino-aprendizagem.

Assim, o referido trabalho tem como objetivo propiciar o desenvolvimento de habilidades técnicas no domínio das ferramentas por softwares oferecidos pelas Tecnologias de Informação e Comunicação (TICs), oportunizando aos acadêmicos, experiências pedagógicas através de projetos de ensino e utilização de mapas conceituais, como técnica de aprendizagem significativa.

\section{Metodologia}

Esta experiência de Estágio Supervisionado foi desenvolvida na cidade de D ourados-M S, caracterizada por 23 escolas estaduais, nas quais foram implantados laboratórios de informática, também denominadas Salas de Tecnologias E ducacionais-STEs, 
cuja finalidade é promover o fazer pedagógico do professor, através do uso dos recursos oferecidos pelo computador.

Considerando que há necessidade de melhorar as habilidades e o domínio das tecnologias educacionais de licenciados recém-formados para o uso adequado das STEs, o referido estágio foi realizado por meio de um curso preparatório para o desenvolvimento de projetos tecnológico-educacionais, através de uma parceria entreo $\mathrm{N}$ úcleo de Tecnologia $\mathrm{E}$ ducacional deD ourados-M S - NTE e a U niversidade Federal da Grande D ourados - U FGD, havendo como público, uma turma de 12 acadêmicos do 4ํano do Curso de Ciências Biológicas - Licenciatura Plena. As atividades apresentaram carga horária total de 70 horas, distribuídas em três etapas: curso preparatório, aplicação da prática de ensino em forma de estágio supervisionado e apresentação de relatos de experiência, como descrito a seguir.

\section{Fase Teórica - Formação:}

O s acadêmicos foram orientados, em um curso de 48 horas denominado "As Tecnologias de I nformação e Comunicação no Ensino de Ciências", a trabalharem conteúdos da disciplina de Ciências, objetivando desenvolver certas habilidades na produção de projetos pedagógicos inserindo a utilização de recursos tecnológicos e aplicando a construção de mapas conceituais, através dos aplicativos oferecidos pelo computador, tais como editor de texto, planilha eletrônica, produção e apresentação de slides, a ferramenta Internet e o Software C mpaTools. É interessante explicar que pelo fator tempo e por considerar que o público envolvido na capacitação ainda não conhecia uma boa parte dos recursos tecnológicos acima citados, o programa $\mathrm{CmpaTools}$ foi apenas apresentado aos acadêmicos, sendo o mesmo reconhecido como excelente ferramenta para a produção de mapas conceituais, havendo o compromisso de cada acadêmico explorar o referido programa para ser aplicado em atividades posteriores.

O curso de capacitação foi ministrado pela professora/ multiplicadora de Ciências do NTE de Dourados, e, em todos 
os momentos, acompanhado pela professora responsável pela disciplina Prática de Ensino de Ciências/U FGD.

D urante esta etapa, os acadêmicos visitaram algumas escolas públicas do município de Dourados, conhecendo a realidade escolar, a direção, a coordenação e professor de Ciências, bem como o seu planejamento de ensino. Desta forma, foi possível escolher as turmas para efetivação do estágio supervisionado e estabelecer, junto ao professor, o tema e o título dos projetos a serem desenvolvidos. A escolha dos temas dos projetos aconteceu de acordo com os conteúdos previstos na grade curricular da escola, respeitando o planejamento do professor regente, possibilitando assim, o desenvolvimento de conteúdo já previsto para o momento, porém, organizados na forma de projetos de aprendizagem, nos quais, em todas as atividades, os alunos foram o alvo principal do trabalho proposto.

O s acadêmicos, após serem capacitados para a utilização de ferramentas oferecidas pelo computador, descreveram os projetos, destinados ao ensino fundamental, apresentando cópias para o N TE, professor de Estágio, coordenação escolar e professor regente.

As atividades práticas do estágio envolveram estudantes do ensino regular (5a a 8a séries) e Educação de Jovens e Adultos - EJA ( 3 a e 4a fase), nas quais foram abordados os seguintes temas: ar, solo, água, saúde, alimentação e ecologia. D entre esses temas, os projetos desenvolvidos apresentaram os seguintes títulos: "O Ar que nos Rodeia" (M inicurso no NTE - estudantes de 5a a 8a séries), "Água e Saúde" (M inicurso no NTE - estudantes de 5a a 8a séries), "R eino das Plantas" (M inicurso no NTE - estudantes de 5a a 8aㅡ séries), "D oenças H umanas Transmitidas pelo Ar, Água e pelos Alimentos Contaminados" (Aulas em escola da rede estadual - 7ạ série), "O s Elementos Q uímicos da Tabela Periódica e os Alimentos" (Aulas em escola da rede estadual - 8a série), "D oenças Sexualmente Transmissíveis" (Aulas em escola da rede estadual - 7’a séries), "H igienização e Prevenção de D oenças" (Aulas em escola da rede estadual - 3a e 4ํㅡ Fases), "O Sistema Sensorial e a Saúde" (Aulas em escola da rede estadual - 
7 a séries), "Solo e D oenças D eterminadas pelas Condições Sociais e H igiênicas da População" (Aulas em escola da rede estadual - 5a série), "A I mportância Biológica e E conômica dos Fungos, destacando os Benefícios e os M al efícios que esses organismos causam ao $\mathrm{H}$ omem" (Aulas em escola da rede estadual - 6 série) e "D oenças Biológicas Transmitidas pelo Solo eÁgua" (Aulas em escola da rede estadual - 3a Fase).

Para elaboração das atividades organizadas na forma de projetos, os estagiários foram orientados pela professora coordenadora do curso no NTE e pela professora responsável pelo estágio supervisionado de ciências; nesta segunda etapa, os acadê micos também foram orientados à produção de relatórios, constando toda experiência adquirida durante o estágio, incluindo análise e reflexões da prática realizada no ambiente escolar.

\section{Fase Prática - Ambiente Escolar:}

A segunda etapa do projeto, com carga horária de 16 horas, aconteceu em escolas da rede pública de ensino inseridas no Projeto Prol nfo. Cada um dos projetos foi aplicado em ambiente escolar e desenvolvido em sala de aula, através da explicação e reflexão de conteúdos contextualizados à realidade dos educandos e posteriormente enriquecidos na sala de tecnologia educacional (STE). Assim, através de construção de mapas conceituais, produzidos pelos aprendizes, sob orientações dos acadêmicos estagiários, mediante aplicativo de apresentações de sides com hiperlinks, os educandos envolveram-se em pesquisas da Internet, tabulações de dados e representações gráficas através de planilhas eletrônicas e relatórios produzidos em editor de textos.

D urante esta fase, os acadêmicos foram acompanhados pela professora de estágio e orientados a produzir os relatórios exigidos.

\section{Fase Analítica - Troca de Experiências:}

A etapa final do estágio contempla quatro (4) horas de duração. Aconteceu através de relatos de experiências adquiridas 
pelos acadêmicos mediante atividades realizadas no NTE e na escola durante o estágio supervisionado.

O s acadêmicos realizaram apresentações orais dos resultados obtidos, utilizando projetor de slides, vídeo, microfone e máquina fotográfica digital. Durante o referido relato, o qual foi aberto para toda comunidade escolar e universitária, os acadêmicos apresentaram os aspectos relevantes do projeto, as deficiências, as expectativas quanto à aprendizagem significativa e as sugestões para trabalhos posteriores.

\section{Resultados e discussões}

O s resultados das atividades desenvolvidas no NTE e em ambiente escolar contemplaram com sucesso os objetivos do trabalho realizado, pois, além de propiciar o desenvolvimento de habilidades técnicas no domínio das ferramentas por softwares oferecidos pelas Tecnologias de I nformação e Comunicação (TICS), oportunizaram aos acadêmicos, experiências pedagógicas através de projetos de ensino e de utilização de mapas conceituais, como método de aprendizagem significativa.

Os relatos das experiências organizadas na forma de projetos de ensino/aprendizagem, desenvolvidos pelos acadêmicos na forma de estágio supervisionado, foram apresentados em 17 de julho de 2004, no salão da Ordem dos Advogados do Brasil OAB - do município de Dourados-MS. A comunidade presente teve a oportunidade de contemplar os resultados dos projetos desenvolvidos na escola, a análise e as reflexões dos estagiários e os depoimentos dos estudantes das escolas públicas envolvidas nos projetos.

D urante as apresentações, os estagiários relataram que o computador foi uma ferramenta auxiliar de alta validade, pois, além de ter propiciado maior enriquecimento dos conteúdos através dos aplicativos, permitiu a construção de mapas conceituais, com organização dos conceitos básicos dos assuntos propostos 
pelos projetos, a partir de hiperlinks com hipertextos de conteúdos abordados em sala de aula.

D eacordo com os relatos de experiência, através de apresentação oral e, posteriormente, escrita na forma de relatório, dos doze estagiários participantes do projeto, seis conseguiram incorporar com ênfase os recursos oferecidos pelo computador às atividades teóricas e práticas, propiciando aos educandos um ambiente de pesquisa, investigação e aquisição de novos conhecimentos. D uas acadêmicas, por questões técnicas da própria escola, não utilizaram a sala de tecnologia, mas, nem por isso deixaram de desenvolver com eficiência suas atividades, utilizando, para tal, outros recursos tecnológicos. Em dados momentos, as acadêmicas inteiraram-se de recursos como o computador e projetor de slides, para auxiliar no complemento dos conteúdos explorados, através de palestras e apresentações de slides.

U m dos acadêmicos que trabalhou numa escola, que ainda não possuía sala de tecnologia, explorou os conteúdos previstos no projeto em sala de aula e em algumas aulas utilizou a sala de tecnologia do NTE, juntamente com os alunos da E ducação de J ovens e Adultos - EJA. D essa forma, promoveu-se o enriquecimento e complemento das atividades desenvolvidas no ambiente da escola.

D urante os trabalhos, três estagiárias ministraram minicursos oferecidos a alunos do ensino fundamental de escolas da rede pública de ensino, havendo como local a própria sala de tecnologia do NTE, onde os estudantes receberam orientações teóricas e práticas sobre conteúdos da disciplina de Ciências, de acordo com níveis de conhecimento. Tais orientações foram enriquecidas com o auxílio de ferramentas oferecidas pelo computador como: pesquisa em sites educacionais da Internet, construção de mapas conceituais e produção de relatórios através de editor de textos, tabulações de dados e representações gráficas mediante planilhas eletrônicas e apresentação dos resultados das atividades através da construção de slides. 
Ainda é válido ressaltar que, durante os relatos de experiências, estudantes envolvidos nos projetos citados deram depoimento, enfatizando a importância dos recursos tecnológicos aplicados às metodologias de ensino para realização de aulas atrativas, diferentes, motivadoras e prazerosas, voltadas para a construção do conhecimento.

Diante dos relatos de experiências, pode-se ressaltar ainda as seguintes observações:

a) Verificou-se que houve valorização por parte dos acadêmicos de haver uma experiência em sala de aula e contato direto com alunos num ambiente escolar, considerando que é através desta aproximação que pode ser analisado o domínio de sala e de conteúdo.

b) O s acadêmicos deram importância ao novo, enfatizando a necessidade de inovações no ensino, pois o ensino de Ciências deve estar cada vez mais próximo da realidade dos alunos, envolvendo conteúdos interessantes e explorados de forma dinâmica.

c) Através do curso fornecido pelo NTE do município de D ourados-M S, foi visível o desenvolvimento das habilidades necessárias para que os acadêmicos pudessem elaborar projetos de Ciênciasutilizando recursos tecnológicos, possibilitando o desbloqueio quanto ao uso dos computadores e maior segurança em utilizar os instrumentos oferecidos pelas TICs, posteriormente como profissional em educação.

d) $O$ estágio aconteceu na realidade da escola, a qual necessita de maior interação das tecnologias no ensino, tornando a prática docente mais moderna e dinâmica, integrada à realidade da sociedade atual.

e) N otou-se a necessidade, entre os acadêmicos, de haver uma carga horária maior, para a execução do estágio de regência. Assim, ficou como sugestão que logo no início das aulas de prática de ensino os acadêmicos sejam encaminhados às escolas públicas para reconhecimento da realidade e do planejamento das aulas de regência junto ao professor titular.

A partir do contexto anteriormente escrito, notou-se o comprometimento dos estagiários na condição de profissionais 
em educação, através do empenho demonstrado junto aos desafios da realidade escolar, em que foi perceptível que o professor precisa estar sempre aberto para mudanças metodológicas, adaptando as novas formas de partilhar o conhecimento, através de projetos, atividades individuais e coletivas, utilizando os avanços oferecidos pelas tecnologias de informação e comunicação às práticas de ensino, reconhecendo seu papel de mediador no processo ensino-aprendizagem.

\section{Considerações finais}

D iante das atividades desenvolvidas pelos estagiários, tanto na sala de tecnologias do NTE, através do curso, quanto nas escolas em que foram aplicados os projetos, na forma de estágio, notou-se a importância da preparação do profissional em educação para lidar com os conteúdos nas diversas áreas do conhecimento, adaptando-os ao cotidiano do educando, buscando compreender, no âmbito educacional, os anseios sociais, econômicos e culturais de cada comunidade escolar.

A través dos relatos da experiência de cada acadêmico envolvido no estágio, foi unânime a constatação de que o planejamento de atividades, o desenvolvimento de projetos de ensino/aprendizagem, o domínio em sala de aula e a flexibilidade diante das situações impostas por cada realidade são fatores importantes para tomadas de decisões, produção do conhecimento e aprendizagem significativa. Verificou-se também, que um dos aspectos relevantes do projeto foi a participação ativa dos estagiários, pois durante as apresentações, os mesmos relataram, com clareza e motivação, os resultados de pesquisa de campo e atividades exploradas em sala de aula. Isto comprova que a aprendizagem deve ser uma construção coletiva, num espaço de diálogo propiciado pela escola, entre educadores e educandos. D essa maneira, pode-se concluir que a participação da comunidade no sistema 
escolar é outro fator que pode contribuir para que a utilização da informática educativa como ferramenta auxiliar junto às práticas pedagógicas na vida cotidiana dos alunos. Portanto, incluí-la como componente curricular nas diversas áreas do conhecimento significa preparar os educandos para a sociedade tecnológica e científica, aproximando a escola cada vez mais da sociedade da informação, da comunicação e do conhecimento.

\section{Referências}

AL MEID A, M ariaE. B. de. 0 computador comoferramenta dereflexãona formação ena prática de professores. Campinas: Papirus, 1997. (mimeo.).

AL M EID A, M aria E. B. de. Educação, projetos, tecnologia e conhecimento. São Paulo: PR OEM , 2002.

AU SU BEL, D avid P., N OVAK, J oseph D .; H ANESIAN , H . (1978). Educational psychology. N ew York: H olt, R inehart and Winston. Publicado em português pela E ditora I nteramericana, R io de J aneiro,1980. Em espanhol por Editorial Trillas, M éxico, 1981. Reimpresso em inglês por Werbel \& Peck, N ew York, 1986.

BRASIL, M inistério da Educação e do Desporto. Parâmetros C urriculares N acionais, Secretariade Ensino F undamental, 1997.

BRASIL, M inistério da E ducação. Parâmetros C urriculares N acionais, Secretaria de E ducação M édia e Tecnológica, 1998.

CLÁUDIO, D. M .; CU N H A, M . L . A snovastecnologiasna formação de professores de matemática. In: CU RY, H . N . (org). Formação de Professores de $M$ atemática: uma visão multifacetada. Porto Alegre: EDIPU CRS, p. 167-190, 2001.

DEM O, Pedro. Educar pela pesquisa. Campinas-SP: Autores Associados, 2003.

- Pesquisa e construção de conhecimento: M etodologia Científica no caminho de $\mathrm{H}$ abermas. R io de Janeiro: Tempo Brasileiro, 2002.

FIOR ENTIN I, D ; CASTR O, F. C. Tornando-se professor de matemática: o caso de Allan em prática de ensino e estágio supervisionado. In: 
FIORENTINI (org). Formação de Professores de M atemática: explorando novos caminhos com outros olhares. C ampinas: M ercado de L etras, $p$. 121-156, 2003.

FRAN T, J. B. Tecnologia, corpo, linguagem: cognição. A naisdol Simpósio Brasileiro de Psicologia da Educação M atemática. Curitiba: UTP, p. 121134, 2001.

FREIRE, F. M. P.; PRAD O, M. E. B. B. Projeto Pedagógico: Pano de fundo para escolha deum software educacional. In: VALENTE, J .A. (org.). 0 computador na Sociedade do C onhecimento. Campinas, SP: U N ICAM PNIED , p. 111-129, 1999.

H ER N ÁN DEZ, Fernando. Transgressão e M udança na Educação: os projetos de trabal ho. Tradução de J ussara H aubert R odrigues. Porto Ale gre: Artmed, 1998.

HER NÁNDEZ, Fernando. A organização do currículo por projetos de trabalho/Fernando H ernández eM ontserrat Ventura. Tradução de J ussara H aubert Rodrigues. - 5. ed. Porto Alegre: Artes M édicas, 1998.

MACIEL, I ra; PAIVA, Jane. (2000) op. cit.

M ACIEL, I ra M . Educação a distância. A mbientesVirtuais. construindo significados. Boletim Técnico do Senac, R io de Janeiro, v. 28, n. 3, p. 3945, set. /dez. 2002.

M ORAN, J. M. Ensino eaprendizagem inovadores com tecnologiasaudiovisuaisetelemáticas. In: M ORAN , J. M .; M ASETTO, M. T.; BEH REN S, M .A. N ovas Tecnologias e M ediação Pedagógica. Campinas: Papirus, p. 11-65, 2000.

M ORAN , JoséM anuel. Contribuiç̧̃̃es para uma pedagogia de educação on line. In: SILVA, M arco. Educação on line: teorias, práticas, legislação, formação corporativa. São Paulo: L oyola, p. 39-50, 2003.

M OREIRA, M .A.; M ASINI, E.F.S. A prendizagem significativa: a teoria da aprendizagem de D avid Ausubel. São Paulo: E ditora M oraes,1982.

M OREIRA, M .A. U ma abordagem cognitivista no ensino da Física. Porto Alegre: Editora de U niversidade, 1983.

M OREIRA, M .A.; BU CH WEITZ, B. N ovasestratégias deensino eaprendizagem: osmapasconceituaiseo Vêepistemológico. L isboa: Plátano E dições T écnicas, 1993. 
MINISTÉRIO DA EDU CAÇÃO E DO DESPORTO/SECRETARIA DO ENSINO FU NDAMENTAL - Parâmetros Curriculares N acionais. 1ํㅡ음os. EnsinoFundamental. CiênciasN aturais. 1997.

PAIS, L. C. Educação Escolar e as Tecn ol ogias da I nformática. Belo H orizonte: Autêntica, 2002.

PENTEAD O, M irian G. N ovos atores, novos cenários: discutindo a inserção dos computadores na profissão docente. In: BICU D O, M . A. V. (org.). Pesquisa em Educação M atemática: Concepções e Perspectivas. São Paulo: Editora U NESP, p. 297-313, 1999.

PONTE , J. P.; SER RAZIN A, L. As novas tecnologias na formação inicial de professores. L isboa: D epartamento de Avaliação, Prospectiva e Planeamento do M inistério das E ducação,1998.

PO N TE, J. P. Tecnol ogias de informação e comunicação na educação e na formação de professores: Q ue desafios? R evista I bero-A mericana de E ducação, 2000.

PONTE, J. P.; O LIVEIRA, H .; VARANDAS, J. M . O contributo das tecnologias de informação e comunicação para o desenvolvimento do conhecimento e da identidade profissional. In: FIORENTINI (Ed.). Formação deprofessores de $M$ atemática: Explorando novos caminhos com outros olhares. Campinas: M ercado de Letras, p. 159-192, 2003.

PRAD O, M . E. B. Brito. Articulação entreáreas do conhecimento etecnologia. Articulando saberes e transformando a prática. In: ALM EIDA, M aria Elizabeth B. de; MORAN, J osé M anuel (orgs). Integração das Tecnol ogias na E ducação. Salto para o Futuro. Secretaria de Educação a D istância: Brasília, Seed, 2005a.

RELA, Eliana; R O CH A, Karla; CARVALH O, M arie Jane. Estágio na formação de professores no contexto das novas tecnologias de informação princípios norteador es e desafios a serem enfrentados. I nformática na E ducação: teoria \& prática, Porto Alegre, v.10, n.1, p. 29-40, jan./jun. 2007.

RIPPER, A. V. O preparo do professor para as novastecnologias. In: O LI VEIRA, V. B. de (org.). Psicopedagogiael nformática, São Paulo, SEN AC, p. 55-84, 1996.

VALENTE, J. A . (org.). Computadores e conhecimento: repensando a educação. Campinas: Gráfica Central da U N ICAP, 1993. 